\title{
Periventricular leucomalacia and neurodevelopmental outcome in preterm infants
}

\author{
C L FAWER, P DIEBOLD, AND A CALAME \\ Centre Hospitalier Universitaire Vaudois, Unité Néonatale et de Développement, Service de Pédiatrie, \\ Lausanne, Switzerland
}

SUMMARY During an 18 month period, 120 preterm infants of 34 weeks' gestation or less were prospectively examined for periventricular leucomalacia (PVL) by cerebral ultrasound. Neurological and developmental assessment was carried out at 18 months of age corrected for prematurity in 82 surviving neonates. The developmental outcome (Griffiths development quotient) was above 80 and similar in infants with normal scans $(n=41)$, isolated periventricularintraventricular haemorrhage $(n=13)$, and post-haemorrhagic hydrocephalus $(n=4)$, and no major handicap was diagnosed in these groups. By contrast, the prognosis was variable and poorer in infants with PVL $(n=24)$ and depended on the extent and site of the lesion. Infants with frontal PVL $(n=13)$ developed normally. Major sequelae $(n=8)$ were closely related to frontal-parietal PVL and frontal-parietal-occipital PVL and could be ascribed to the presence of cysts as well as to a persistent hyperechogenic ultrasonographic PVL appearance. A relation between size and site of the lesion and type and severity of the handicap was established.

Brain ultrasonography is used extensively for the detection of cerebral lesions in the newborn. Its validity for the diagnosis of periventricular leucomalacia (PVL) has been debated. ${ }^{1-3}$ Based on correlative studies between ultrasound appearances and postmortem observations, it is clear that accurate identification of PVL can be achieved. ${ }^{45}$ None the less, the precise predictive value of brain ultrasonography in the diagnosis of PVL is unclear. ${ }^{67}$

The main purpose of this study was to describe prospectively the type, site, and extent of PVL and to evaluate the neurodevelopmental outcome of children with PVL at 18 months of age compared with children with normal scans or with periventricular-intraventricular haemorrhage $(\mathrm{PVH})$.

\section{Patients and methods}

A total of 120 infants of 34 weeks' gestation or less were scanned in the neonatal unit of this hospital. Twenty two died in the neonatal period (seven with normal scans, nine with PVH, five with PVL, and one with cerebral malformation). Sixteen were lost to follow up (13 with normal scans, one with meningitis, and two with PVH). The remaining 82 patients were grouped according to ultrasound diagnosis and followed up to 18 months of age. Group A $(n=24)$ comprised infants with PVL with or without $\mathrm{PVH}$, group $\mathrm{B}(\mathrm{n}=41)$ infants with normal scans, group $C(n=13)$ infants with isolated PVH without PVL or ventricular dilatation, 10 of whom had subependymal haemorrhage and three intraventricular haemorrhage, and group D $(n=4)$ infants with arrested or progressive posthaemorrhagic obstructive hydrocephalus without PVL.

Included among the survivors were all but one of 54 children who were the subjects of a previous report that addressed outcome up to 12 months of age. ${ }^{8}$ The child not included was disregarded because of the omission of regular sequential scanning. There was no change in the interpretation of brain scans from the original report.

The birth weight, gestational age, sex distribution, and ultrasonographic appearances in the four groups are shown in Table 1.

Ultrasound scans. Infants were prospectively scanned with an American Technical Laboratories mechanical sector scanner and $7.5 \mathrm{MHz}$ transducer. Scanning was performed through the anterior fontanelle in the coronal and parasagittal planes as soon 
Table 1 Neonatal data according to brain ultrasound findings in the four groups

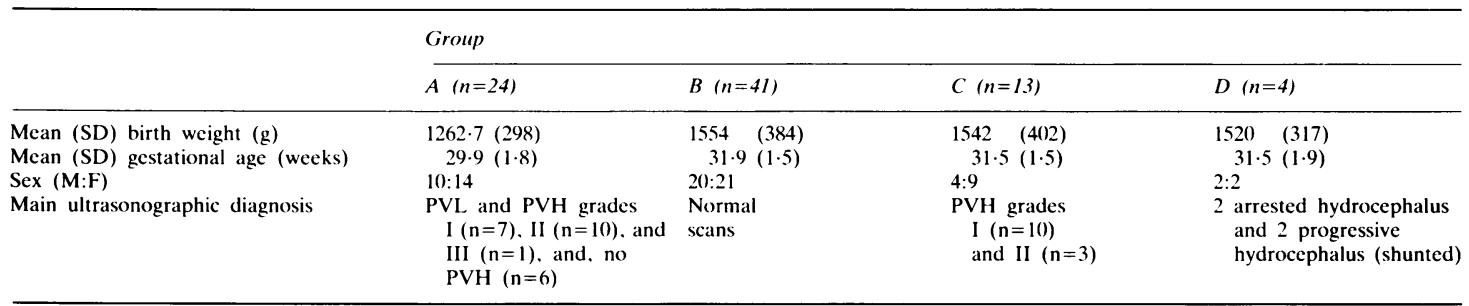

PVL= Periventricular leucomalacia: $\mathrm{PVH}=$ Periventricular-intraventricular haemorrhage.

as the infant was admitted, daily during the first week of life and thereafter once weekly or more if necessary until discharge from hospital.

Ultrasound definitions and classifications, as well as diagnostic methodology, remained uniform throughout the 18 months. The degree of severity of PVH was defined according to the three grading system of Levene. ${ }^{9}$ The size of the ventricles was measured and related to the centile chart ${ }^{10}$ and the pattern of dilatation was described separately (transient, arrested, or shunted). If the measurement was greater than two standard deviations from the mean ventricular dilatation was diagnosed. The diagnosis of hydrocephalus was made when shunting was required or when the size of the ventricles remained markedly enlarged, well above two standard deviations.

PVL was defined in two stages. The early stage occurred within the first days of life and consisted of a characteristic triangular increased echogenicity visible for at least several consecutive days in both coronal and parasagittal planes in the vicinity of the external angles of the lateral ventricles in the periventricular white matter. The late stage was observed from the second to the 10-12th week of life and consisted of areas of reduced echogenicity, resolving progressively into cystic cavitation. ${ }^{4}$

Ultrasound changes described in the survivors were consistent with the diagnosis of PVL as they were similar to ultrasound scans of infants whose diagnosis was confirmed at postmortem examination. Doubtful or transient increased echogenicity and a posterior periventricular halo ${ }^{11}$ were not considered as definite PVL, and these infants were classified for the follow up in the normal group or PVH group, depending on the other ultrasonographic appearances.

The size and site of PVL changes were described separately and defined as frontal leucomalacia when frontal areas only were involved (Fig. 1), frontalparietal leucomalacia when frontal-parietal areas were affected (Fig. 2), and frontal-parietal-occipital leucomalacia in cases of extensive lesions involving the entire periventricular white matter from anterior to the frontal horns and from posterior to the occipital horns (Fig. 3).

Neurological assessment and follow up. Gestational age was determined from maternal dates and Dubowitz scores. ${ }^{12}$ The babies were then examined by staff not involved in the neonatal care at ages corrected for prematurity of $3,6,9,12$, and 18 months. The follow up examination consisted of a detailed neurological examination, ${ }^{13}{ }^{14}$ an assess-

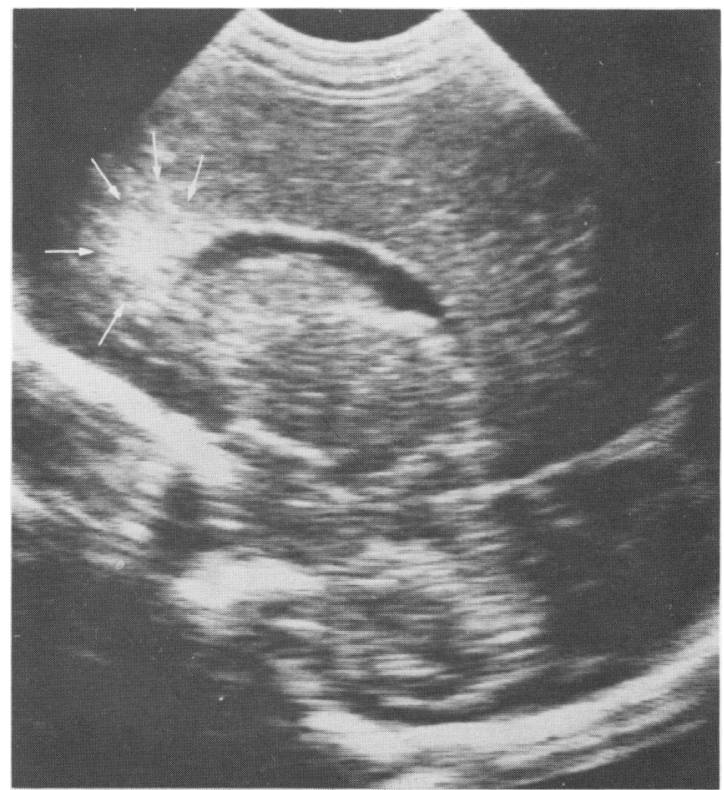

Fig. 1 Parasagittal ultrasound scan, showing a focal increased echogenicity located anteriorly to the frontal horns of the lateral ventricles. This lesion evolved into cystic formation within two weeks. 


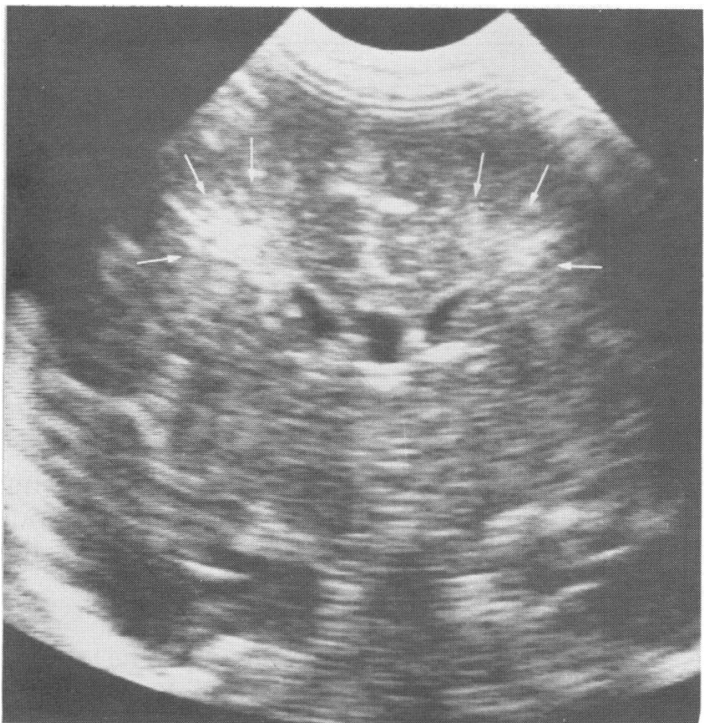

Fig. 2 Coronal ultrasound scan of the middle fossa, showing a characteristic triangular increased echogenicity involving the parietal areas. Subsequent development of cysts was noted.

ment of development using the Griffiths scale, ${ }^{15}$ and an evaluation of vision and hearing according to the Stycar method. ${ }^{1617}$ Children were regularly examined by an ophthalmologist and if necessary referred for audiometric assessment (auditory brain stem response and audiometry).

Neurological outcome was classified as normal or as major handicap (spastic diplegia, quadriplegia, hemiplegia, severe auditory and visual impairment, and developmental delay (developmental quotient $(\mathrm{DQ})<80)$ ).

\section{Results}

Neurodevelopmental outcome in relation to ultra- $\frac{S}{9}$ sonographic diagnosis. The overall incidence of major $\frac{\mathrm{C}}{\mathrm{O}}$ handicaps was $9.7 \%$. The mean (SD) DQ was $88 \frac{\bar{\sigma}}{\bar{\alpha}}$ $(21.3)$ in group $\mathrm{A}$, where lesions of PVL were $\vec{\sigma}$ diagnosed. Eight of the 24 children had a major 2 handicap (three had cerebral palsy, one mental $\%$ retardation, and four multiple handicaps). By con- $\overrightarrow{0}$ trast all children in groups $\mathrm{B}, \mathrm{C}$, and $\mathrm{D}$ had a $\mathrm{DQ}>80$, and no child had a major handicap. The $\vec{\omega}$ mean (SD) DQs in groups B, C, and D were 99.4 $(5 \cdot 0), 101 \cdot 7(4 \cdot 0)$, and $98.7(6.9)$, respectively. The 응 difference in the mean DQ in group $A$ compared with groups $\mathrm{B}, \mathrm{C}$, and D was significant $(\mathrm{p}<0 \cdot 01, \stackrel{?}{-}$ Mann-Witney U test).

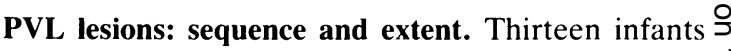
were found to have PVL changes in the frontal $\vec{c}$ areas, six in the frontal-parietal areas, and five in the frontal-parietal-occipital areas. The sequence of PVL changes and the extent of the lesion related to size and site of the ultrasonographic appearances are $\vec{\omega}$ shown in Table 2. Seventeen infants were noted to $\stackrel{\infty}{v}$ have the echogenic stage of PVL within the first week of life and seven presented only with the late stage, with small cystic cavitations of 1-2 mm, close to the external angles of the lateral ventricles.

The most common sequence of PVL changes was $\stackrel{2}{8}$ increased echogenicity that resolved into cystic $\stackrel{\mathbb{Q}}{\Omega}$ formations (11 cases). In five infants sequential $\overrightarrow{0}$ scanning revealed a persistent increased echo- 3 genicity lasting at least two weeks. This was located in the frontal areas in three infants, in the frontal-o parietal areas in one, and in the frontal-parietaloccipital areas in one. Cystic changes were not identified in spite of serial ultra-sonography in these patients. The extent of the lesion was related to the
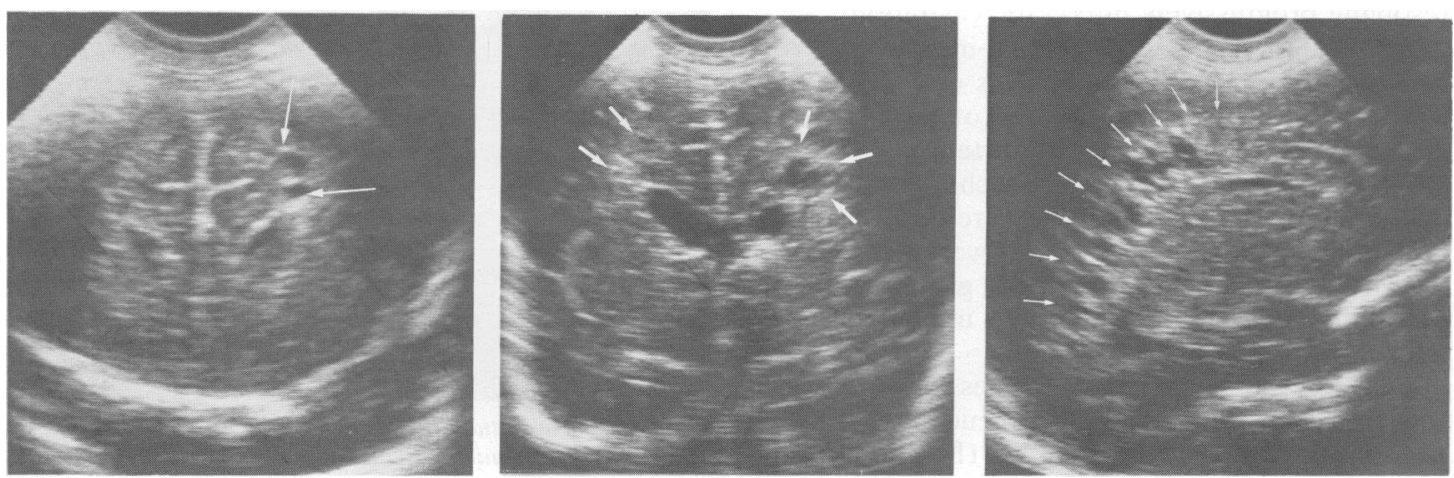

Fig. 3 Multiple cystic formations in the frontal (coronal scan (left), parietal (coronal scan) (middle), and occipital areas (parasagittal scan) (right). 
Table 2 Periventricular leucomalacia: localisation, sequence, and extent

\begin{tabular}{|c|c|c|c|c|}
\hline \multirow{2}{*}{$\begin{array}{l}\text { Type of } \\
\text { leucomalacia }\end{array}$} & \multicolumn{2}{|c|}{ Sequence of PVL changes } & \multicolumn{2}{|l|}{ Extent of lesion } \\
\hline & $\begin{array}{l}\text { Early stage } \\
\text { (1st week) }\end{array}$ & $\begin{array}{l}\text { Late stage } \\
(2 n d-12 \text { th week) }\end{array}$ & $\begin{array}{l}\text { Size } \\
\text { (echogenuc or cystic area) }\end{array}$ & Site \\
\hline \multirow{3}{*}{$\begin{array}{l}\text { Frontal } \\
\qquad(n=13)\end{array}$} & 5 echogenic & Cystic & Cysts of $1-2 \mathrm{~mm}$ & \\
\hline & 3 echogenic & Echogenic & $\begin{array}{l}\text { Small focal increased } \\
\text { echogenicity }\end{array}$ & $\begin{array}{l}\text { Anteriorly to or around the frontal } \\
\text { horns }\end{array}$ \\
\hline & $5-$ & Cystic & Cysts $1-2 \mathrm{~mm}$ & \\
\hline \multirow{3}{*}{$\begin{array}{l}\text { Frontal-parietal } \\
\qquad(n=6)\end{array}$} & 2 echogenic & Cystic & Multiple small cysts $(1-2 \mathrm{~mm})$ & $\begin{array}{l}\text { Around external angles of lateral } \\
\text { ventricles in frontal and parietal } \\
\text { areas }\end{array}$ \\
\hline & 1 echogenic & Cystic & 1 large right cyst & Right parietal area \\
\hline & $2-$ & Cystic & Small cysts of $1-2 \mathrm{~mm}$ & Both frontal-parietal areas \\
\hline \multirow{3}{*}{$\begin{array}{l}\text { Frontal-parietal-occipital } \\
\qquad(n=5)\end{array}$} & 1 echogenic & Cystic & Cysts of $2-5 \mathrm{~mm}$ & Both frontal-parietal-occipital areas \\
\hline & 2 echogenic & Cystic & Large cysts of $>1 \mathrm{~cm}$ & Both frontal-parietal-occipital areas \\
\hline & 1 echogenic & Echogenic & Extensive increased echogenicity & Both frontal-parietal-occipital areas \\
\hline
\end{tabular}

$\mathrm{PVL}=$ Periventricular leucomalacia.

site of PVL. Frontal lesions were all focal or of small size. Most of the infants with frontal-parietal and frontal-parietal-occipital damage had large lesions.

Neurodevelopmental outcome in relation to PVL lesions. The distribution of the DQ on the Griffiths scale with regard to the site of PVL is shown in Figure 4. All children with frontal leucomalacia were normal and had a DQ above 80. Major handicap was found in three of the six children with frontal-parietal leucomalacia. The three normal children had only small cystic formations $1-2 \mathrm{~mm}$ in diameter clustered around the external angles of the lateral ventricles. Infants with extensive lesions involving the frontal-parietal-occipital areas had a poor prognosis, and most had a DQ below 80 .

Major handicaps and PVL lesions. Patients with PVL lesions and major handicaps are described in Table 3. All but two infants had PVH in association with PVL lesions. Ventricular dilatation was also common and two infants required ventriculocardiac shunting. PVL was detected within the first days of life in its echogenic stage in each infant. The echogenic areas resolved into cystic cavitations of various size in all but two infants (cases 1 and 6). Case 8 developed signs of cerebral atrophy (enlarged extracerebral spaces and prominent interhemispheric and sylvian fissures) after a very rapidly progressive hydrocephalus, which might suggest diffuse hypoxic-ischaemic parenchymal damage. The cysts were large $(>1 \mathrm{~cm}$ in diameter) in cases 2,5 , and 7 . Multiple small cysts $1-2 \mathrm{~mm}$ in diameter surrounding the external angles all along the ventricular system were found in two patients (cases 3 and 4). Most of the children had extensive involvement of the frontal-parietal-occipital areas (cases 4-8).

Six children with parietal lesions developed moderate to severe motor dysfunction: two had a spastic diplegia, one hemiplegia, and three spastic quadri-

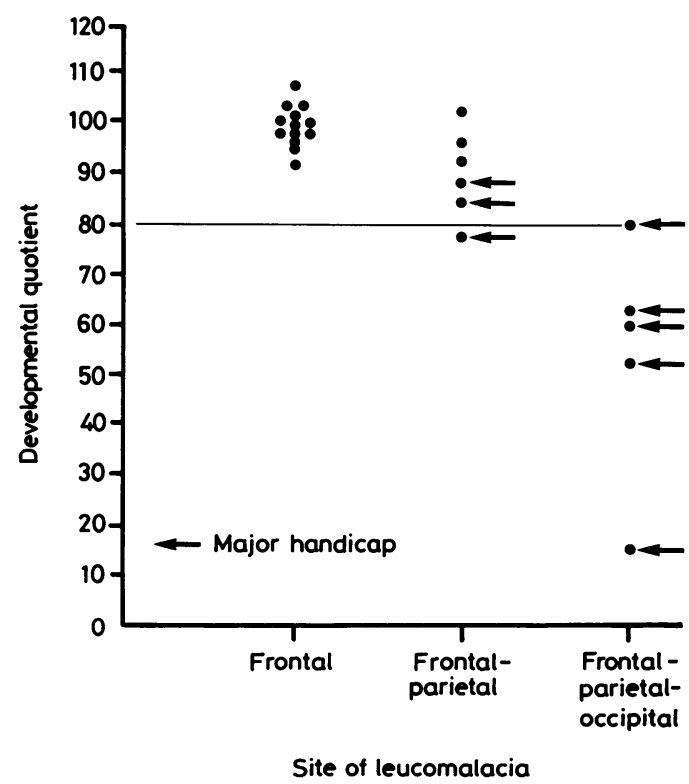

Fig. 4 Development quotients on the Griffiths scale according to the distribution of periventricular leucomalacia. 


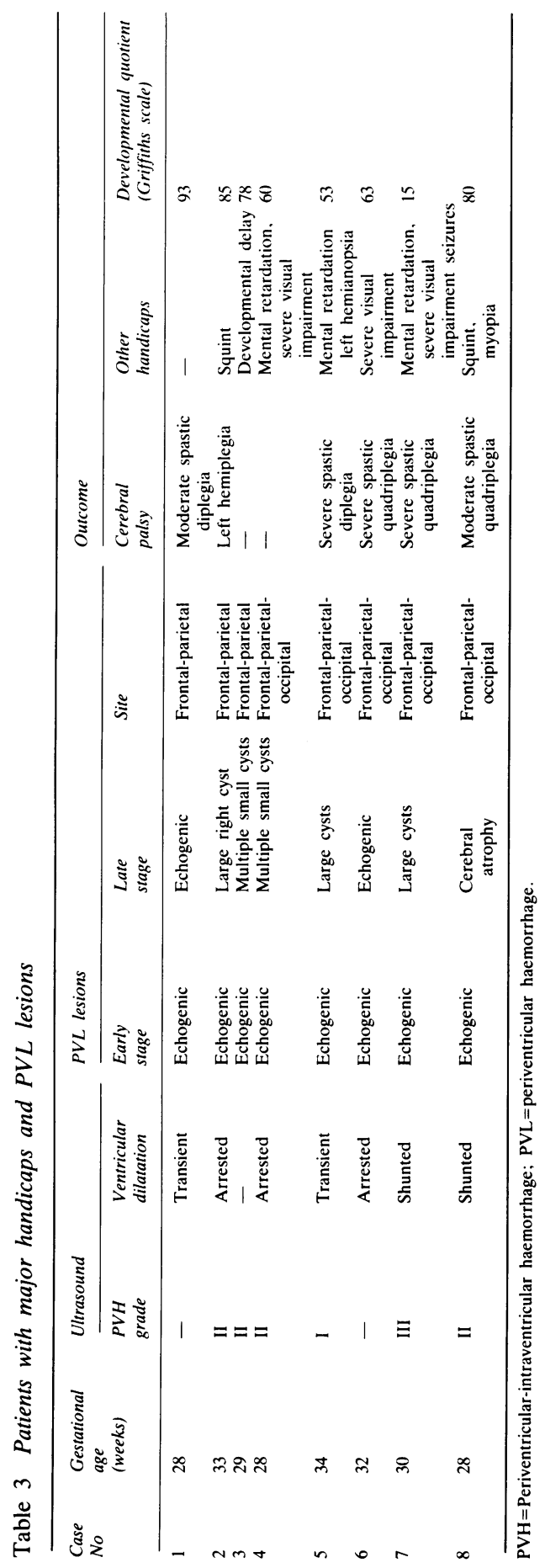

plegia. Only two children with minor parietal involvement (small cysts) did not have cerebral palsy (cases 3 and 4). The five children with extensive lesions in the frontal-parietal-occipital areas presented with multiple handicaps. Severe visual impairment was found in four infants with occipital lesions: three had uncoordinated eye movements, nystagmus, reduced visual acuity, or no apparent vision and one had poor visual activity and a left hemianopsia related to right occipital PVL. Hearing was normal in all. Development was delayed $(\mathrm{DQ}<80)$ in most of them.

\section{Discussion}

The present study indicated that major neurodevelopmental sequelae were closely related to the presence of PVL. Our data also confirmed previous reports describing a good prognosis for uncomplicated, small, or isolated periventricular-intraventricular haemorrhage. ${ }^{8}{ }^{18-22}$ The interpretation and importance of the ultrasound scan findings, and more particularly increased periventricular echogenicity, has been disputed. ${ }^{11}{ }^{23}{ }^{24}$ The diagnosis of PVL by ultrasonography and assessment of the prognosis of this lesion requires (1) systematic and sequential scanning in the neonatal period to allow precise detection and description of the lesions, (2) the use of mechanical sector scanner with high frequency transducer to visualise both the periventricular white matter and parenchyma and to identify small lesions, and (3) a follow up programme of all scanned infants whatever the ultrasonographic diagnosis to assess and compare prospectively their neurodevelopmental outcome.

We have previously reported in an autopsy correlation study that the early changes of PVLthat is, increased echogenicity corresponding on microscopy with acute coagulation necrosis ${ }^{5}$ evolved into two different patterns. ${ }^{4}$ The most common change was cystic degeneration with well circumscribed echofree areas. The second change appeared as a persistent increased echogenicity (Fig. 5) lasting two to four weeks and was probably caused by gliosis with microcalcifications and small cysts less than $2 \mathrm{~mm}$ in diameter ${ }^{4}{ }^{25}$ not identified by our scanning equipment. These observations strongly suggest that PVL and haemorrhage originating from the germinal layer are two distinct entities because of their respective topography and microscopic changes. Germinal layer haemorrhage may extend into the ventricular system and parenchyma. In our experience, however, 'parenchymal haemorrhage' is rare.

The extent of the damage was related to the size of the hyperechogenic area and the size, number, 


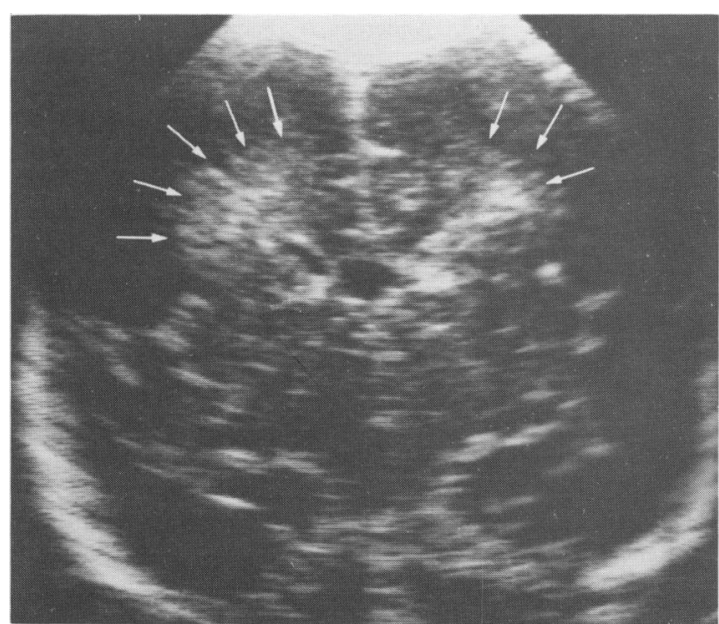

Fig. 5 Coronal scan at 2 weeks of age, showing a persistent increased echogenicity in the parietal areas.

and site of the cysts. As already described in neuropathological reports ${ }^{25}{ }^{26}$ PVL varied considerably in frequency and site. The preferential distribution in our study was in the frontal areas, anteriorly to the frontal horns. The periventricular white matter of the parietal regions, at the level of the foramen of Monro in the centrum semiovale, was also often affected. Involvement of the occipital radiations, at the trigone of the lateral ventricles, was always associated with extensive damage located in the frontal and parietal areas. Lesions were most often bilateral and multiple. These results support the idea that hypoxic-ischaemic injuries occur in the 'watershed' areas of the central and cortical vascular supplies and in the boundary zones between the main cerebral arteries. ${ }^{27-29}$

Major neurodevelopmental handicaps were strongly associated with the presence of PVL. A clear relation could be established between the type and severity of the dysfunction and the site and extent of the cerebral lesions. Parietal involvement led to motor dysfunction. The more extensive the damage the more severe the cerebral palsy. A severe visual impairment was found in most infants with occipital lesions. Infants with frontal PVL or small focal changes of PVL, however, had a good prognosis. None of them had a major handicap and at 18 months their development was considered normal.

Surprisingly, two children who were sequentially scanned had only the persistent hyperechogenic appearance of PVL with no cystic cavitation, yet they presented with severe sequelae. Leech showed a broad variety of microscopic alterations of PVL, which suggested a gradient of insult.$^{30}$ Our findings supported this hypothesis and seemed to indicate that the persistent increased echogenicity is likely to reflect permanent microscopic changes resulting in neurologic deficit. Furthermore, small cysts $1-2 \mathrm{~mm}$ in diameter, if multiple, might also represent a marker of a more diffuse parenchymal ischaemia, causing a severe developmental delay or a mental retardation (cases 3 and 4).

We conclude that serial brain ultrasonography in the newborn has an important role in the prediction of later neurodevelopmental outcome among preterm infants. It is as important to describe the persistent echogenic appearance of PVL as the cyst formation because major handicaps in our study could be ascribed to both these lesions. A relation between site and extent of the lesions and type and severity of the handicap was shown. Further follow up studies are needed to assess fine psychometric abilities and cerebral function in children with focal or frontal PVL who were apparently 'normal' at 18 months.

We thank Dr A Anderegg for her collaboration, the neonatal nursing staff for help, L Arrazola for the statistical analyses, and $\mathrm{M}$ Marion for secretarial help.

Financial support was provided by the Swiss National Science Foundation No 3.895.0.83.

\section{References}

${ }^{1}$ Levene MI, Wigglesworth JS, Dubowitz V. Hemorrhagic periventricular leukomalacia in the neonate: a real-time ultrasound study. Pediatrics 1983;71:794-7.

${ }^{2}$ Hill A, Melson GL, Clark HB, Volpe JJ. Hemorrhagic periventricular leukomalacia: diagnosis by real-time ultrasound and correlation with autopsy findings. Pediatrics 1982;69:282-4.

${ }^{3}$ Nwaesei CG, Pape KE, Martin DJ, Becker LE, Fitz CR. Periventricular infarction diagnosed by ultrasound, a postmortem correlation. J Pediatr 1984;105:106-10.

+ Fawer CL, Calame A, Perentes E, Anderegg A. Periventricular leukomalacia: a correlation study between real-time ultrasound and autopsy findings. Neuroradiology 1985;27:292-300.

5 Rushton DI, Preston PR, Durbin GM. Structure and evolution of echo dense lesions in the neonatal brain. Arch Dis Child 1985;60:798-808.

6 Dubowitz LMS, Bydder GM, Mushin J. Developmental sequence of periventricular leukomalacia. Arch Dis Child 1985;60:349-55.

${ }^{7}$ Weindling AM, Rochefort MJ, Calvert SA, Fok TF, Wilkinson A. Developmental of cerebral palsy after ultrasonographic detection of periventricular cysts in the newborn. Dev Med Child Neurol 1985;27:800-6.

${ }^{8}$ Fawer CL, Calame A, Furrer MT. Neurodevelopmental outcome at 12 months of age related to cerebral ultrasound appearances of high risk preterm infants. Early Hum Dev 1985:11:123-32.

${ }^{9}$ Levene MI. Fawer CL, Lamont RF. Risk factors in the development of intraventricular haemorrhage in the preterm neonate. Arch Dis Child 1982:57:410-7.

10 Levene MI, Starte DR. A longitudinal study of posthaemorrhagic ventricular dilatation in the newborn. Arch Dis Child 1981:56:905-10. 
36 Fawer, Diebold, and Calame

1 Grant EG, Schellinger D, Richardson JD, Coffey ML, Smirniotopoulous JG. Echogenic periventricular halo: norma sonographic finding or neonatal cerebral hemorrhage. $A J N R$ 1983;4:43-6.

12 Dubowitz LMS, Dubowitz V, Goldberg C. Clinical assessment of gestational age in the newborn infant. $J$ Pediatr 1970;77:1-10.

13 Amiel-Tison C. A method for neurologic evaluation within the first year of life. Curr Probl Pediatr 1976;7:1-50.

${ }^{14}$ Prechtl HFR, Beintema DJ. The neurological examination of the full-term newborn infant. Little Club Clinics in Developmental Medicine 1964: No 12.

15 Griffiths R. The abilities of babies: a study in mental measurement. Amersham: Association for Research in Infant and Child Development, 1976.

16 Sheridan MD. Manual for the STYCAR hearing tests. Windsor: NFER Publishing Company, 1968.

17 Sheridan MD. Manual for the STYCAR vision tests. Windsor: NFER Company, 1969.

18 Palmer P, Dubowitz LMS, Levene MI, Dubowitz V. Developmental and neurological progress of preterm infants with intraventricular haemorrhage and ventricular dilatation. Arch Dis Child 1983;57:748-53.

19 Papile LA, Munsick-Bruno GOTR, Schaefer A. Relationship of cerebral intraventricular hemorrhage and early childhood neurologic handicaps. J Pediatr 1983;103:273-7.

${ }^{20}$ Stewart AL, Thorburn RJ, Hope PL, Goldsmith M, Lipscomb AP, Reynolds EOR. Ultrasound appearance of the brain in very preterm infants and neurodevelopmental outcome at 18 months of age. Arch Dis Child 1983;58:598-604.

21 Catto-Smith AG, Yu VYH, Bajuk B, Orgill AA, Astbury J. Effect of neonatal periventricular haemorrhage on neurodevelopmental outcome. Arch Dis Child 1985;60:8-11.
22 Calame A, Fawer CL, Anderegg A. Perentes E. Interaction between perinatal brain damage and processes of normal brain development. Dev Neurosci 1985:7:1-11.

${ }^{23}$ Stewart AL, Hope PL, Hamilton PA, Baudin J, Wyatt JJ, Reynolds EOR. Increased periventricular echodensities in very preterm infants and prediction of carly neurodevelopmental outcome. Pediatr Res 1985:19:1084.

${ }^{24}$ Laub MC, Ingrisch H. Increased periventricular echogenicity (periventricular halos) in neonatal brain: a sonographic study. Neuropediatrics 1986;17:39-43.

${ }^{25}$ Banker BQ, Larroche JC. Periventricular leukomalacia of infancy: a form of neonatal anoxic encephalopathy. Arch Neurol 1962;7:386-410.

${ }^{26}$ Shuman RM, Selednik LJ. Periventricular leukomalacia. A one-year autopsy study. Arch Neurol 1980;37:231-5.

${ }^{27}$ De Reuck J, Chattha AS, Richardson EP. Pathogenesis and evolution of periventricular leukomalacia in infancy. Arch Neurol 1972;27:229-36.

${ }^{28}$ Pape KE, Wigglesworth JS. Haemorrhage, ischemia and the perinatal brain. London: Heinemann, 1979:100-7. (Clinics in Development Medicine No 69/79.)

${ }^{29}$ Levene MI, Williams JL, Fawer CL. Ultrasound of the infant brain. London: Heinemann, 1985:76-92. (Clinics in Developmental Medicine No 92).

30) Leech RW, Alvord EC. Morphologic variations in periventricular leukomalacia. Am J Pathol 1974;74:591-602.

Correspondence to Dr C-L Fawer, Unité Néonatale, Service de Pédiatrie, CHUV, 1011 Lausanne, Switzerland.

Received 4 August 1986 